\section{An Interdisciplinary Architectural Pedagogy for Social Relevance}

\section{Kelum Palipane}

University of Melbourne

Janet McGaw

University of Melbourne

\section{INTRODUCTION}

We live in a time of rapid geo-political change that is expected to accelerate rather than stabilise over the coming decades: More than half the world lives in urban areas, a figure expected to rise to $68 \%$ over the next 30 years. ${ }^{1}$ Cities are denser and more socially complex than ever before. Rural to urban internal migration continues, but a substantial driver of population transitions is a consequence of inter-national immigration, some of it forced. In fact, there are currently 65 million displaced people in the world; the largest figure in history. These increasingly complex conditions require architects to practice a new kind of critical consciousness about the socio-economic, envi-ronmental and demographic multiplicities in which they work. It's no longer enough to concentrate on the conditions of a site defined by the lines of property ownership. Architects need to adopt a contex-tually relevant praxis that responds to the multiscalar effects of our changing social condition. To that end, we argue, the emerging gen-eration of architects will need knowledge and methods - often inter-disciplinary - that enable them to read and represent these social complexities and address them through critical design responses. This paper presents a pedagogical approach for a foundational transdisci-plinary design studio within a new generalist undergraduate degree in design in which this pedagogical challenge is addressed. It is a core subject in the pathway to professional a master's degrees in architec-ture, landscape architecture and urban design.

The first author is the subject coordinator of the foundational design studio, Design Studio Alpha, and the second author set up the curriculum approach for the architecture pathway in the degree as a whole. Design Studio Alpha's curriculum was informed by the lead author's interdisciplinary research for design that considers cul-turally conditioned, multiplicitous bodies as a device through which to interrogate the social and spatial implications of occupying space at multiple scales. It incorporates ethnographic methods alongside more traditional architectural conventions. The paper will demon-strate selected learning outcomes by unpacking specific examples of student work while discussing the unique challenges of coordi-nating a large and diverse undergraduate design studio that is core to different disciplines. Key pedagogical challenges include how to design a studio curriculum that embeds more general disciplinary skills and knowledge while engaging in complex contextual issues; how to encourage students to engage conceptually with politics of space; and how to teach students to see the traces of social occu-pation of space that are often ignored in normative practice so that they can conceptualise appropriate, sensitive spatial and program-matic responses. The paper concludes by arguing that it is possible to embed fundamental knowledge relevant to the profession while engaging in complex (albeit imagined) contextual issues.

\section{COMPLEXITIES WITHIN THE STUDIO AND WITHOUT}

Universities reflect the social complexities that are unfolding at a global scale. Five million tertiary students were enrolled in uni-versities outside their home country in 2014: around 20 percent in institutions in the USA, the most popular destination for 


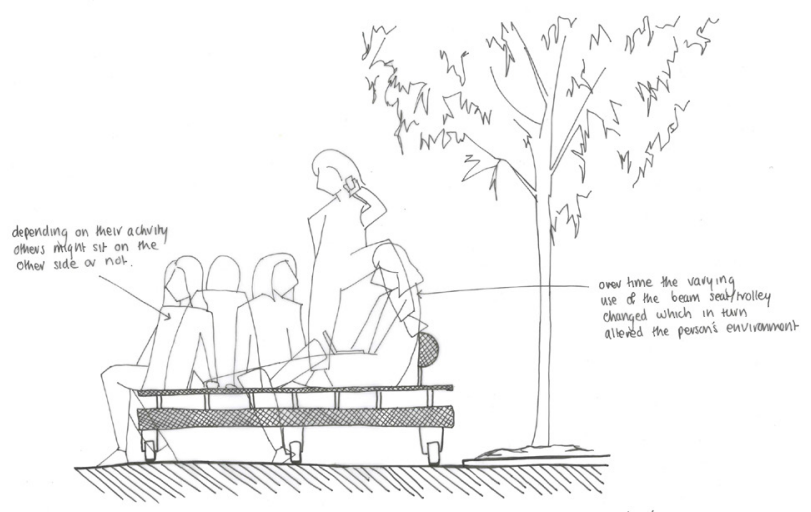

CONTROLLING ONE'S ENVIRONMENT EAST SIDE MSD - 2PM 2/08/17
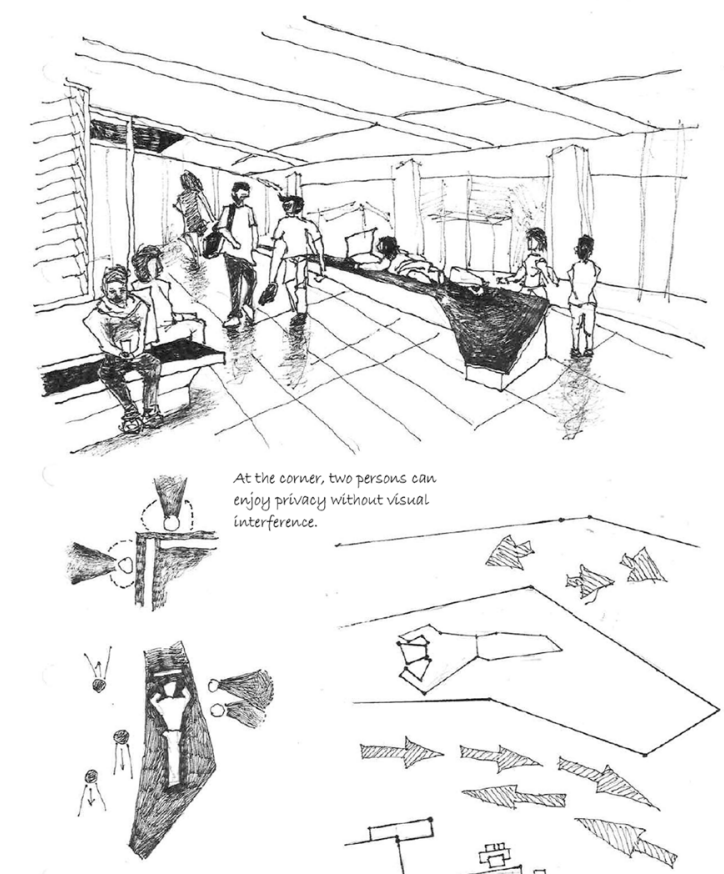

A person lies face down on the bench. The width of the bench fit's her body width, thus she can occupy a section for her private leisure.

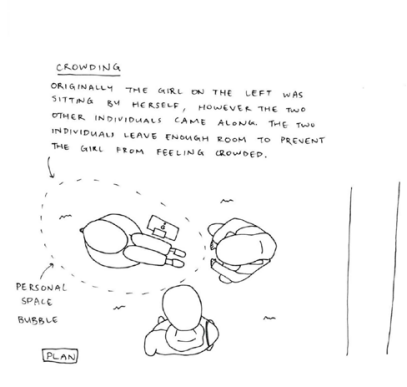

without visual
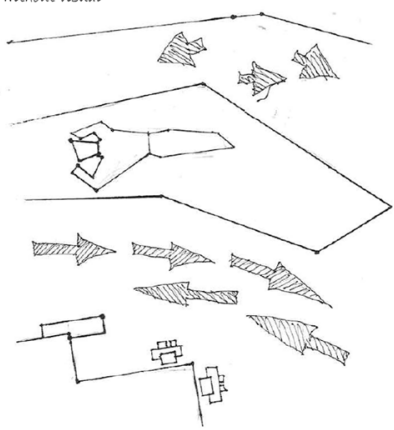

The bench seperates the are into two sections with one being a direct passage from one door to another where people move fast, another being a "private" passage whe people can linger and see the exibitions.
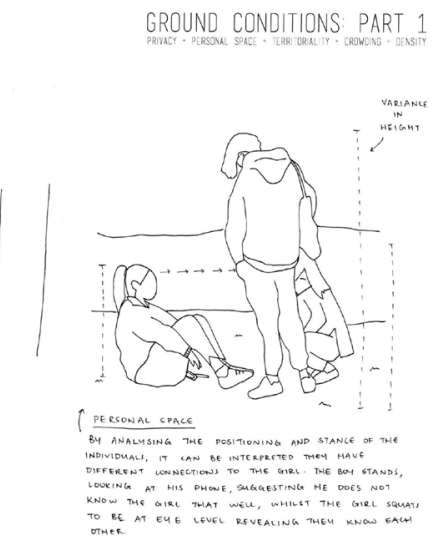

Figure 1. Relationships between social bodies and the built enviroment interrogated through sketches. Drawings by Chloe Dutton (top), Jihao Fan (middle), Kristie Anderson (bottom). international students, followed by 10 percent in the UK and 6 percent in Australia, where they make up around a third of all students. $^{2}$ In Australia the transformations have been particularly evident as tertiary education was either free or heavily subsidised from the 1970s until 2000, when full fee paying places for international students were first made available. There are now 1.2 million tertiary students in Australia. A third of them are international. Within the Bachelor of Design cohort, stu-dents come from diverse cultural backgrounds. Responding to these movements based on market demands, higher education has incre-mentally changed and is increasingly about information and skills acquisition, where degrees are a means of positioning oneself in a competitive global marketplace. Tertiary education has little mean-ingful connection to the lived experience of students. This disconnect between the knowledges that are produced in tertiary education and the lived experience of students has added significance with increas-ingly diverse and non-traditional cohorts of students. One might even argue that in current tertiary education we are actually selling a specific epistemological approach based on Western knowledge traditions to 'clients' who are asked to value it above their own traditional forms of knowledge. One that potentially reinforces existing systems of oppression. We argue however that the critical mass of international students is allowing us an opportunity to value alterna-tive epistemologies and ways of knowing, including knowledges that have been traditionally marginalised. The following section illustrates how an interdisciplinary approach can allow students to read and interpret complex conditions, with opportunity to interweave prior knowledges, all the while acquiring disciplinary specific knowledge.

\section{THE STUDIO APPROACH:TRACING SOCIAL OCCUPATION TO UNCOVERTHE POLITICS OF PLACE}

Design Studio Alpha has up to 320 enrolments per semester, spread across 24 studio groups. They meet for 3 hours per week with a tutor and attend a one-hour lecture. Additional learning materials, (such as readings and video instructions for analogue and digital representa-tional techniques), are provided through an online learning platform. Of the 320 students, approximately $60 \%$ selfidentify as Architecture Major students, 30\% as Landscape Architecture and the remaining across Urban Planning, Urban Design and other Majors.

The studio is structured into two key stages: the first 5 weeks of a 12-week semester entails learning from existing built spaces that stu-dents can easily access (e.g. areas of the building in which the school is located and other sites within the university premises) The design brief includes applying a functional and socio-spatial analysis of the site. The socio-spatial is defined as the interplay between social bod-ies and space. Students analyse familiar spaces in and around their school within this framing through themes and methods introduced in the weekly lectures. These themes correspond to specific scalar implications for the body; the civic considered at 1:500 scale, the com-munal at 1:100 and at 1:50 and the individual body at $1: 5$. 
Students are introduced to simple, immersive ethnographic methods such as 'participant and non-participant observation' and aspects drawn from the lead author's research interest, which includes small-scale placemaking practices of multicultural communities and their implications for architectural design. Insights from this research that relate to the occupation of space are introduced such as: how the tac-tical and temporal use of space allow multiple social realities to exist in one space; how expression of identity occurred through bodily pos-tures and gestures; how the unprogrammed appropriation of affor-dances in the built environment reflect the specificities of the bodies involved; and how the appropriation of such elements allows agency for users. The aim of introducing these themes was to allow students to gain insight into the intersectional relationship between time, space and the social body. These experiential exercises encourage stu-dents to learn and apply fundamental design principles and anthropo-metric and ergonomic data and to critically reflect on their impact on human behaviour and the experience of space.

During the preliminary stage of the studio students sketch elements defining space, spatial progression, relationships between bodies and between bodies and the built environment through issues of privacy, personal space and territoriality (see Figure 1). As these are culturally conditioned spatial concepts, we found students are able to draw on their own backgrounds and experiences to make sense of what they were observing. In this way, students' multicultural backgrounds are affirmed as valuable epistemologies and ways of knowing. They are a conscious attempt to cultivate what bell hooks calls an 'engaged pedagogy'. ${ }^{3}$ She says that everyone's presence in the class should be acknowledged in some way to build a 'classroom commu-nity' where we recognise the value of each individual voice. ${ }^{4}$ It also creates an opportunity where tutors can engage in a self-reflexive dialogue, re-framing the role of teacher and student in which both are seen as co-creators of knowledge.

Spatio-temporal occupations of space by groups vs individuals across the site are captured in the civic scale - 1:500 - analysis of the study area. These drawings enable students to identify organisational strategies of form and space and consider their influence on social practices. The 1:100 and 1:50 scale plans and sections enable students to consider the spatial implications of the sun path and the impact of light and shade at a microclimatic scale (Figure 2). Focusing on the interfaces between buildings and open spaces, the drawings reveal an understanding of the microclimatic conditions created by the built environment and adjacent vegetation. Students were expected to articulate how this impacted on people's behaviour.

Students consider materiality and detail through the study of small-er objects, such as seating, encountered by bodies at 1:5 scale (Figure 3). While the drawings are essentially traditional measured draw-ings, students are encouraged to include different bodies engaged with the object in different ways and consider how materials register the inhabitational patterns and the histories of occupation and use through wear and other marks.

During the second half of semester students design an urban terrain and a suite of micro-infrastructure within it for a group of people seeking refuge. The imagined, dystopian scenario presents a chal-

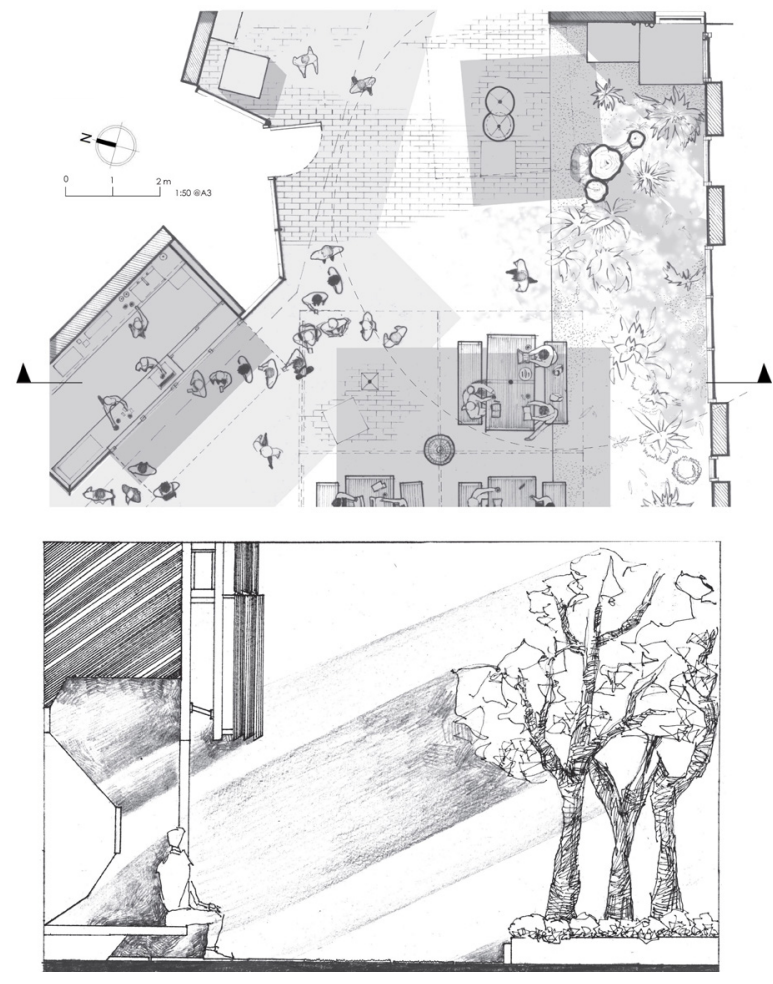

Figure 2. Microclimate is analysed through 1:100 and 1:50 scale plans and sections. Drawings by Yupeng Gao (top) and Jihao Fan (bottom).

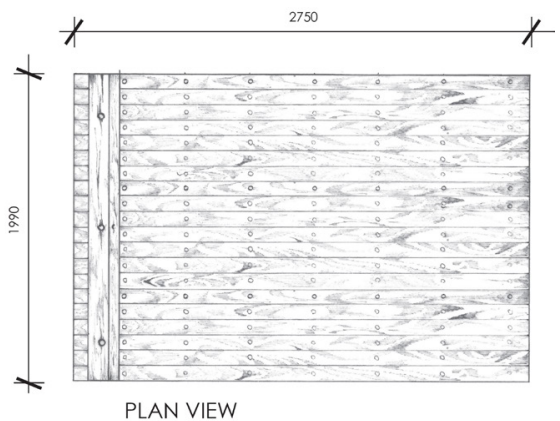

PLAN VIEW
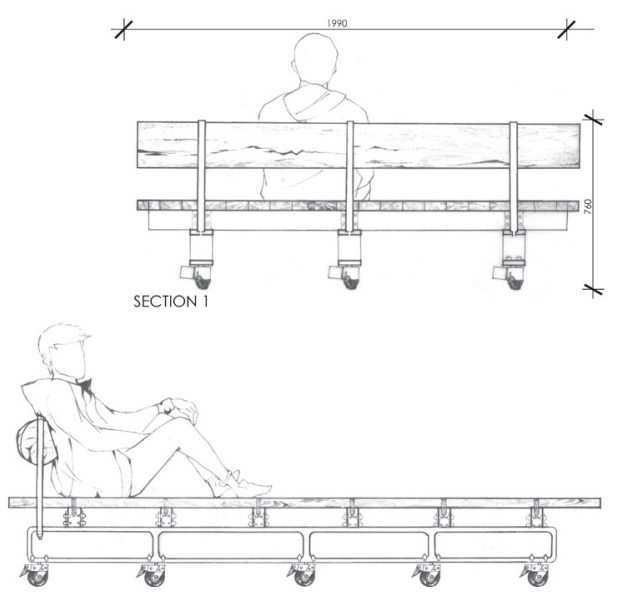

Figure 3. Materiality and detail are considered through an object study. Drawing by Yupeng Gao 
enge to Australia's recent history of responding to the global refu-gee crisis with offshore processing. The site was a public urban square situated in a central location in Melbourne not far from the university campus. The students are asked to design a programme for emerg-ing socialities and economies within this urban context - defined as a place for exchange. They select a protagonist from a given set of four influenced by Ben Rawlence's book City of Thorns: Nine Lives in the World's largest Refugee Camp. ${ }^{5}$ The characters include 'Guled', a young, quick, artful leader of a gang of youths; Marion, an elderly woman with limited mobility who runs a cottage industry and looks after a 4 year old grandchild; Nisho, a 27 yr old woman who is a leader, activist and teacher; and Subhi, a 7 year old who lives with his ill mother and teenage brother, is a bit of a dreamer and loves stories. The characterisation enables students to imagine their protagonists spe-cific bodily needs and specific ways of moving through and occupying space. Students are expected to respond to this through their design decisions. For example, how the terrain could be navigable by some-one that is elderly or how it might be explored by a child.

\section{THE STUDIO APPROACH: BUILDING-IN CORE DISCIPLINARY SKILLSAND KNOWLEDGE}

A key challenge has been to find intersections between the various disciplines - architecture, landscape architecture, and urban design for which Studio Alpha is a core subject and to introduce appropri-ate core knowledge that is common to them all. Attempts are made through the parameters set for formal and material explorations. The site, an existing urban unpaved open space is around $100 \times 150 \mathrm{~m}$ and consists of a gentle slope across the site. Instead of a specif-ic structure, the students are asked to manipulate the ground plane through land-forming exercises. They consider the surface of the ground as a datum, considering space above and below this in design explorations. A number of techniques are introduced like carving out, infilling, stepping and folding, to manipulate the ground plane. The micro-infrastructure is to incorporate complimentary works that sup-port social and economic activity at a micro scale into the civic ter-rain. This includes urban street furniture and other urban elements such as lighting, pathways, shading elements that could be appro-priated in multiple ways by changing publics at different times of the day. Designs have to show exploration of at least two materials: an architectural building material such as timber, steel and concrete which architecture students are learning about in their construction technology subject) as well as earth or vegetation. Detailing points of intersection is an important aspect of design resolution.

Students revisit the scalar implications of the socio-spatial and functional issues studied earlier in the semester and apply this knowl-edge within this new brief and context. The concept of programme is introduced and broken down into three levels: key use of the urban terrain as a place where incoming refugees will congregate; two types of zone, one more public where community formation and emerg-ing economies unfold and the other more private, where people can retreat and hide; and individual elements or microstructure that can be appropriated for a range of purposes by different people. Students are challenged to consider the openended possibilities of economic and social 'exchange'. How might they imagine exchange unfolding in a refugee camp? They needed to consider places for buying and selling goods, bartering and other alternate economies, but also plac-es where knowledge and stories are shared or protests are mounted. And to consider the various ways their protagonists might want to 'retreat', from hiding from authorities, to finding places of privacy in the public realm. They are shown precedents where designers have used camouflage as an architectural device to create hidden places.

At the broader site scale illustrated in 1:500 scale models (Figure 4), students utilise formal organisational strategies and ordering prin-ciples such as axis, hierarchy, linear and centralised organisation as well as knowledge of sun path and orientation to site aspects of the brief. At this scale, they were also challenged to consider how a large crowd can occupy and move through the space. The designs of the micro-infrastructure explored at 1:100 and 1:50 scales privilege the human scale and carefully consider anthropometrics. Perspective vignettes of spatial progression are drawn at 'standing figure' view-point to encourage consideration of how their various protagonists may use and experience space. Detail and materiality and how the body engages with the design are encouraged to be detailed at 1:5 scale (Figure 5). In the interaction with built space, the importance of materiality is illustrated as bodies interacted with and became affect-ed by the nature of materials.

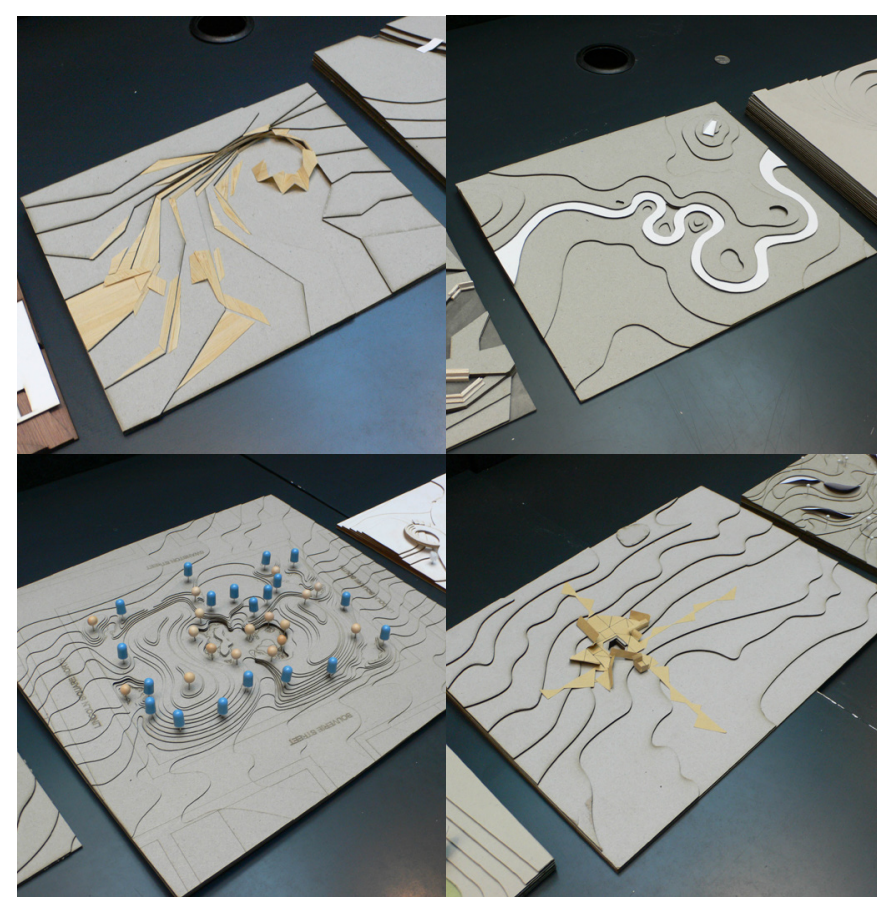

Figure 4. Models illiustrating broad scale organisational strategies of urban terrain and micro-infrastructure (clockwise from top left) Briean Ranchhod, Michaela Prunotto, to be indentifie , Kester Chong. 

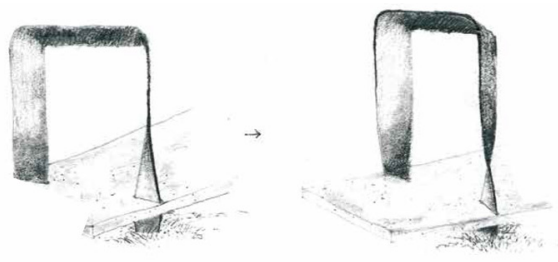

$<$
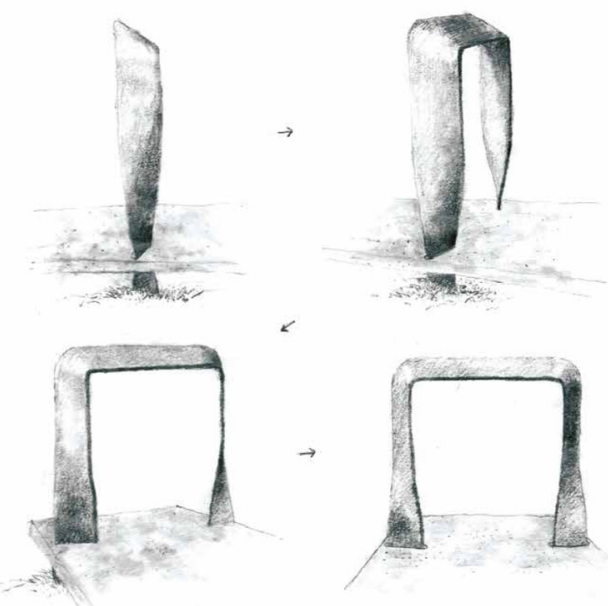

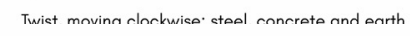

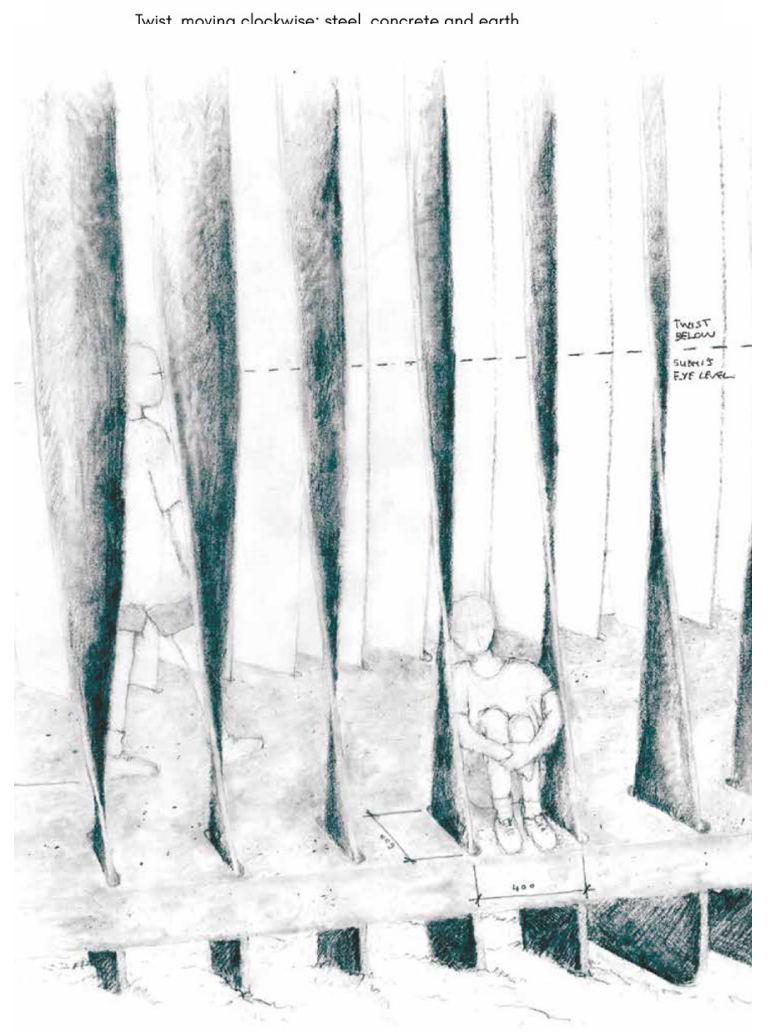

The covert - dimensioning of blades in relation to Subhi
$1 \cdot 10$

Figure 5. Detail, materiality and how bodies engage with the microinfrastructure are considered. Drawings by Michaela Prunotto.

\section{STRENGTHS, LIMITATIONS AND STUDENT RESPONSES}

Many of the student work included in the figures here feature hand-drawing. While this was mandatory in the first half of the semes-ter, it wasn't in the second. We found that students incorporating hand-drawing techniques were able to inject a layer of nuanced detail and vitality to their design representation that was absent from purely digitally produced work. Most students however develop a work flow between the two, drawing by hand and enhancing the work using graphic design software.

Inevitably, in a large cohort of students there will be a wide and varying range of capabilities and skills. While the studio aims to engage students in the critical consideration of societal issues in an innovative way through the design decisions they make, there are always examples of superficial engagement and a tendency towards depolitisisation of issues. There may be several reasons for this. Firstly, as first year students mostly ranging in age between 17-20, the level of maturity students bring to these issues may be limited. But as Diana Agrest writes, it may also be reflective of the reductive propensities of architecture as a discipline. Of the relationship between design (defined as architecture and urban design) and cultural systems, Agrest writes: "Design, considered as both a practice and a product, is in effect a closed system - not only in relation to culture as a whole, but also in relation to other cultural systems such as literature, film, painting, philosophy, physics, geometry, etc. Properly defined, it is reductive, condensing and crystallizing general cultural notions with-in its own distinct parameters." ${ }^{\prime}$ She further elaborates saying that cul-ture is usually related to design through formal analogies that bring with them an inherent reductivism which is what makes it possible to align them with architecture's particular paradigms. ${ }^{7}$

Students also encountered difficulty at the transition from analysis to synthesis stages in the studio. This way of structuring a studio where there is an initial analysis stage and then the design exploration stage is not new, and the associated challenges are well document-ed. ${ }^{8}$ It was hoped however that by revisiting the same scalar implica-tions through the same architectural conventions from the first stage to the second, students gained the benefit of a iterative design and production process.

The transformative potential and the long- term impact on design thinking; for example on how students document and respond to human needs or their sensitivity to spatial politics is difficult to assess. The authors elicited written feedback from the cohort of students who are now graduating from the Bachelor of Design degree after 3 years of study:

"Through rigorous analysis of both human-to-human interaction and our body's relationship to space, time and objects, I quickly saw that architecture does not exist in a vacuum; there is a site, there are human beings with varying wants and needs, and all ought to be considered. Reflecting on past work produced after Studio Alpha, every project was approached with curiosity regarding the site and how its conditions might affect human behaviour and inhabitation. I now find myself considering even the simplest elements of my designs, like the bevelling of a seat edge or the orientation or position of the outdoor 
furniture and the implications this may have on the social interaction of its users." - Joshua Budgen, Bachelor of Design

"As a student fresh out of high school and with very little exposure to design thinking, Alpha was pivotal in forming how I saw and approached design. I began to see design as something which could be visually simple and clear, but rich in detail and meaning. Consequently, my preferred approach to design grew to embrace a conscientious sensibility, in terms of both ideas/narrative and representation. I undertook site visits with an eagle eye for traces of human behaviour. Additionally, I pushed the representation and refinement designs so that they were generous, evocative, detaildriven and tac-tile. I like to think that they were imbued with a vitality and character. My hope, as instilled by Alpha, is that in crafting a 'living architecture', the quality (and equity) of life of those experiencing the architecture will be optimised." - Michaela Prunotto, Bachelor of Design

We are however aware of the lack of rigor in assessing impact in this way. A more effective way may be reinforcing this type of student feedback by mapping key indicators across the successive under-graduate studios.

\section{CONCLUSION}

This volume of proceedings is organised around the thematic of the 'the hunch' in teaching practice. A 'hunch' while defined as an uninformed guess, is usually the starting point for a researcher a moment of intuitive understanding before a hypothesis is formulat-ed. In this instance, a hunch which became research for design by the authors was able to inform teaching practice. Peter Downton defines research for design as increasing "...knowledge of another field...with the expectation that at least some ideas will be able to be appropri-ated in a way that will be useful to design and designing." " In this way, the interdisciplinary curriculum design outlined in this paper that draws from the authors interdisciplinary research practice, which in turn draws on methods and conceptualisations ethnography, human geography and cultural studies, built awareness or sensitivity in stu-dents to issues of urban diversity, identity, and social equity allowing critical and imaginative engagement with the hypothetical social and political context in which they were working.

It was also revealed that students arrive partially formed and have their own rich and particular histories and experiences that they can draw on to design places for diverse groups. A lot of students expand on their own 'hunches' to consider such issues as climate change, urban isolation and loneliness, and agency for youth in public space. Focusing on the human body and its social and spatial implications within a narrative, enable threads of broader, more complex societal issues to be woven in to their designs. Students also move beyond a typical phenomenological engagement with the body, which is often stripped of inherent contingencies such as gender, age and ethnicity, becoming aware of its socio-cultural implications. In this way the cur-riculum aims to make explicit the social relevance of design, and to also link this awareness with design decisions by embedding key dis-ciplinary knowledge and processes within the curriculum.
Interrogating pedagogical practice by building on the conceptual

frameworks of Paulo Friere's work ${ }^{10}$ hooks calls to 'educate for critical consciousness'11 and writes that, "[Feminist] education for critical consciousness is rooted in the assumption that knowledge and criti-cal thought done in the classroom should inform our habits of being and ways of living outside the classroom." ${ }^{12}$ In architectural educa-tion this may mean the development of practitioners that are armed with the knowledge, skills and aptitudes to navigate the increasingly complex conditions that they are required to practice in. To cultivate this, curriculums across architecture schools need to allow for a diver-sity of ideas; fostering alternative ways of conceptualising space and approaching design. Interdisciplinary design research can play a piv-otal part in this. It would not only harness the potential of increasingly diverse student cohorts but can be the key in making tertiary educa-tion a place of multiple epistemes, contributing towards a broader aim of producing thoughtful and socially aware citizenry.

\section{Notes}

1. United Nations Department of Economic and Social Affairs (2018) "68\% of the world population projected to live in urban areas by 2050, says UN", 16 May, 2018. Available at https:// www. un.org/development/desa/en/news/population/2018revision-of-world-urbanization-prospects.html

2. Jie Zong and Jeanne Batalova "International Students in the United States," Migration Information Source (Washington: Migration Policy Institute, May 2016). Available at https://www.migrationpolicy.org/article/ international-students-united-states.

3. bell hooks, Teaching to Transgress: Education as the Practice of Freedom (New York: Routledge, 1994), 15.

4. hooks, Teaching to Trangress, 8.

5. Aspects of the brief such as the consideration of a group of people re-forming socialities and economies in a new context, and the use of a protagonist as a narrative drive for the project was influenced by the book City of Thorns: Nine Lives in the World's Largest Refugee Camp by Ben Rawlins.

6. Diana, I. Agrest, Architecture from Without: Theoretical Framings for a Critical Practice (Cambridge, Massachusetts: MIT Press, 1991), 32.

7. Agrest, Architecture from Without, 49-50.

8. Ashraf, M. Salama, Spatial Design Education: New Directions for Pedagogy in Architecture and Beyond (Burlington: Ashgate Publishing Company, 2015).

9. Peter Downton, Design Research (Melbourne: RMIT Publishing, 2003), 18.

10. Paulo Friere's seminal work, Pedagogy of the Oppressed (1968) proposed an emancipatory approach to education through a synthesis of critical reflection and praxis. .

11. hooks, Teaching to Trangress, 127.

12. hooks, Teaching to Trangress, 194. 